\title{
Estratégias de visibilidade e ações docentes no Twitter
}

\author{
Visibility strategies and teacher actions on Twitter
}

Camila Lima Santana e Santana* Instituto Federal de Educação, Ciência e Tecnologia Baiano

Edvaldo Souza Couto** Universidade Federal da Bahia

Resumo $\mathrm{O}$ artigo resulta de uma pesquisa que analisou estratégias de visibilidade e ações docentes utilizadas por professores brasileiros no Twitter. Trata-se de um estudo qualitativo, de cunho netnográfico, realizado através de observação encoberta e análise de tweets de um grupo que possui conta ativa no Twitter. $\mathrm{O}$ argumento central é que a visibilidade no Twitter é um capital social forjado por meio das estratégias que os sujeitos instituem nos Sites de Redes Sociais. Esse capital é singular, considerando que estar ativamente na rede, opinando, tecendo considerações, compartilhando, constitui-se ação educativa e resulta em valorização social e econômica. $\mathrm{O}$ estudo conclui que a visibilidade mediada no Twitter é uma forma de alcançar valorização social na dimensão docente, pois alcançar visibilidade é acumular tipos de capital social, sendo, portanto, uma estratégia profissional.

PALAVRAS-CHAVE: Tecnologia educacional; Redes sociais; Twitter; Visibilidade; Ação docente.

Abstract This paper is result of a search that aimed to analyze the visibility strategies and teacher actions used by Brazilian teachers on Twitter. The article is a qualitative study, ethnographic, made through covert observation and tweet analysis of a teachers group that have active account on Twitter. The main argument is that the visibility on Twitter is a social capital wrought by means of strategies that the individuals established on Social Networks Sites. This capital is singular, seeing that being active on the network, giving opinions, doing some considerations, sharing, constitutes educational action and results in social and economic valorization. The study concludes that the mediated visibility on Twitter is a way to achieves the social valorization on teachers dimension, inasmuch as to achieve visibility is to accumulate some kind of social capital, being, therefore, a professional strategy.

KEYWORDS: Educational technology; Social networks; Twitter; Visibility; Teacher action. 


\section{Introdução}

As redes sociais digitais instauram a era da colaboração, o uso de etiquetas (as tags), que funcionam como filtro, o compartilhamento de conteúdos em tempo real, que amplificam os modos de interação e conexão entre os atores da rede, implicando, neste caso, em maior visibilidade. Quanto mais conectado forem os sujeitos nos Sites de Redes Sociais - SRS, maior a chance de obter informações específicas que estejam circulando, bem como, maior o alcance das informações e conteúdos que eles disponibilizam na rede. A visibilidade é um valor por si só.

Analisar essas estratégias e práticas é importante para compreender de maneira mais substancial os próprios SRS e suas implicações na sociedade atual. O desejo e o ato de mostra-se, de ser visto, reconhecido não são frutos da internet simplesmente, mas são potencializados e ampliados a partir da apropriação de seus espaços pelos sujeitos que a constituem.

Este artigo é resultado de uma pesquisa em que as práticas e estratégias de visibilidade são as construídas por professores no Twitter. O objetivo da pesquisa foi analisar as estratégias de visibilidade utilizadas por um grupo de professores, a partir de suas interações e ações docentes no Twitter. O principal argumento que desenvolvemos é que a visibilidade no Twitter é um capital social forjado por meio das estratégias que os sujeitos instituem no SRS. Ser visível na rede indica uma valorização social preponderante na cibercultura. No caso de docentes, este valor tem uma importância singular, considerando que estar ativamente na rede, opinando, tecendo considerações, compartilhando, constitui-se ação educativa.

\section{O contexto: redes sociais, visibilidade e Twitter}

Os SRS se tornaram um fenômeno da cibercultura a partir dos anos 2000. Enquanto fenômeno cultural, eles afetam as práticas sociocomunicativas cotidianas em escala mundial e engendram novos valores, resgatam outros e constituem espaços de trocas e produções.

O advento tecnológico favorece as ações do tornar-se visível e o status de valorização social à luz da projeção midiática. $\mathrm{O}$ valor, significado do sujeito e seu reconhecimento social estão vinculados às estratégias que utilizamos nos espaços de mídia, especialmente nos SRS, que popularizam o acesso à internet, o alcance do visível enquanto capital social.

As redes são formas de representação das interações, trocas, compartilhamentos, interligações, constituem-se em metáfora estrutural para a conexão entre máquinas, pessoas, ideias e informações. Optamos por entender que os espaços de constituição de redes sociais na internet, não são a rede social em si. São, portanto, Site de Redes Sociais - SRS. Boyd e Ellison (2007) conceituam SRS como serviços baseados na web que permitem aos usuários construir um perfil dentro de um sistema específico e restrito, relacionar outros usuários e poder interagir com eles. 
A visibilidade é um valor cobiçado na atualidade. Ser notado, conhecido nos sites mais populares tem uma relevância significativa na cibercultura. A visibilidade é característica do que pode ser visto e está relacionada à visão no sentido físico, considerando as peculiaridades espaço-temporais que o sujeito se encontra: condições climáticas ou de distância, por exemplo.

É neste contexto que os SRS assumem um papel fundamental, pois torna acessível um grupo grande de representações simbólicas, opiniões, eventos, imagens, vídeos, ações através de compartilhamentos e publicização. As conexões entre sujeitos, a produção e consumo de conteúdos se amplificam em frações de segundos na rede. Esse alargamento nas possibilidades de visibilidade transforma os modos como as pessoas se comunicam, se relacionam e vivem. Entendemos que para alcançar visibilidade, especialmente, na rede, não é suficiente apenas publicizar conteúdo. São fundamentais estratégias que tornem as informações visíveis, rastreáveis e interpretáveis.

$\mathrm{Na}$ internet, são muitos os ambientes onde as pessoas, de todas as idades, condições econômicas e graus de escolaridade transformam as pequenas ações do dia a dia em performances dignas de serem vistas e acompanhadas (SANTANA E COUTO, 2012). Usualmente associa-se essa cotidiana espetacularização do sujeito a categorias específicas como artistas ou celebridades da mídia. Temos identificado cada vez mais que essas práticas não são exclusivas de grupos específicos. O sujeito na cibercultura é esse ator social dos SRS, independente de sua atuação profissional. Os docentes, sujeitos desta pesquisa, valem-se também de estratégias que forjam performances que são acompanhadas, seguidas, compartilhadas e que, consequentemente, atribuem valor social a estes sujeitos.

As estratégias utilizadas pelos atores das redes constituídas nos SRS faz com que seja forjado um imaginário a partir das leituras que os atores fazem um dos outros, isto é, a partir do acompanhamento dos compartilhamentos e trocas estabelecidas. As ações docentes, de naturezas diversas, têm um propósito quando publicizadas num site como o Twitter, com alto número de usuários, em franco crescimento no Brasil e que servem como vitrine para os atos de exibição e atuação dos sujeitos que possuem um perfil no SRS.

A possibilidade de vínculos unilaterais é um dos elementos que torna o Twitter, especificamente para este trabalho, um sistema complexo adaptativo, cujas características envolvem a falta de controle centralizado imposto, a natureza autônoma dos usuários, a alta conectividade entre os usuários e a causalidade em rede não linear de iguais que influenciam iguais. "A conectividade always on" é, de forma cada vez mais abrangente, o fio invisível que se multiplica entrelaçando consciências, espaços, perguntas, desejos" (SANTAELLA e LEMOS, 2010, p.55).

O Twitter inaugura a terceira geração da Web nos contextos dos SRS, visto que além das características de potencial de viralidade e conectividade always on, associa dois outros elementos: o da integração com outras redes e a disponibilização de aplicativos para mobilidade. Diferente de outros SRS, "no Twitter o foco encontra-se 
na qualidade e no tipo de conteúdo veiculado por um usuário específico [...] Nele deparamo-nos com uma ecologia complexa de veiculação de ideias" (SANTAELLA E LEMOS, 2010, p. 67).

As redes de atores sociais no Twitter são formadas basicamente pela ação de follow, o que significa seguir usuários. Assim, o tuiteiro tem a rede dos perfis que ele segue (following) e a rede dos seus seguidores (followers). Esses atores podem fazer parte das duas redes, mas não necessariamente, já que não há a exigência de reciprocidade.

Orihuela (2011) define esse modo de comunicação como assimétrico, pois as relações estabelecidas entre os usuários são optativas, com arquitetura variável e descentralizada. É síncrono, pois é caracterizado pela velocidade da timeline e pelas possibilidades de interação entre usuários de diferentes dispositivos, aplicativos e extensões, tornando o Twitter uma plataforma fácil e de rápido movimentação de mensagens, como uma rede viral. O Twitter é curto, global, hipertextual, intuitivo e social.

\section{Percurso metodológico}

A opção metodológica foi a de uma pesquisa qualitativa, de cunho netnográfico, utilizando as técnicas de observação encoberta, e a técnica de análise dos tweets, tendo como instrumento a matriz de análise, produzida a partir da observação e da pesquisa teórica que apontaram as categorias a serem analisadas.

Essa opção metodológica trata de análise descritiva e analítica resultante da investigação de campo que estuda as culturas, espaços e estruturas online emergentes, mediadas por computador. A escolha dos sujeitos da pesquisa foi feita a partir da imersão no Twitter e do acompanhamento de perfis considerando, inicialmente, as seguintes ações e critérios: Busca por hashtags específicas ligadas à atividade docente, como \#amoserprofessor, \#souprofessor e \#vidadeprofessor, visto que o uso destas hashtags indicam que os professores fazem algum uso docente no Twitter; observação de perfis que se apresentam no Twitter como professores; Perfis que utilizem os termos "professor", "professora", "prof" no username; Perfis com posts diários; Análise de atividade segundo o Tweet Reach ${ }^{1}$ considerando aqueles que possuam grau de exposição superior a 14 mil, visto que buscamos professores potencialmente visíveis. Após esses filtros e da observação das interações dos sujeitos, selecionamos dez professores tuiteiros, que constituem o corpus de sujeitos desta pesquisa.

Com o corpus definido, realizamos observação encoberta nos perfis e coletamos os tweets no período de cinco meses, de janeiro a maio de 2014. As análises dos tweets e dos contextos de interação foram realizadas por meio de Análise Textual Discursiva. Ao todo foram cerca de 8.863 (oito mil oitocentos e sessenta e três) tweets.

Na perspectiva de Kozinets (2002), o primeiro pressuposto do estudo netnográfico é o ingresso cultural. O que significa imersão no espaço de pesquisa de forma efetiva. Nesta etapa da pesquisa, muitos estudiosos da etnografia relatam a importância de diário de campo. Neste trabalho, não utilizamos este recurso de forma separada, por considerar que o próprio Twitter funciona como o registro do campo, em 
uma perspectiva reflexiva analítica, como pontua Amaral (2009). Contudo, utilizamos mapas e esquemas que representaram, desenharam os registros encontrados durante a observação. A etapa seguinte, aliada a pesquisa bibliográfica, consistiu na coleta de dados (LASTA \& BARRICHELLO, 2013). O objetivo desse acompanhamento foi observar os sujeitos e coletar as amostras de análises. Por último, procedeu-se a análise dos dados coletados, ou seja, os tweets mais significativos à pesquisa foram printados, sistematizados e classificados de acordo com as taxonomias escolhidas e matrizes de análises criadas para a referida análise textual. Para realização desta análise, apropriamo-nos das propostas de procedimentos utilizados pela análise textual discursiva enquanto metodologia de análise de dados e informações de caráter qualitativo com a finalidade de produzir novas compreensões sobre fenômenos e discursos.

\section{Análises e resultados}

A manutenção de uma conta no Twitter, assim como em outros SRS, se configura estratégia de resposta dos sujeitos contemporâneos às novas demandas sociais e culturais, que sustentam novas formas de ser e estar no mundo. Junto com essas formas de sociabilidade, outros valores fazem mais sentido e são desejados pelos sujeitos. Valores, na dimensão do capital social, como a visibilidade, por exemplo, são perseguidos pelos atores que se apropriam dos SRS como espaços de interação e exibição de suas performances pessoais e profissionais. No Twitter, não é diferente. A representação do sujeito se dá a partir de um conjunto de fatores que envolvem, "dizer quem sou", "o que produzo", "o que compartilho", "quem eu sigo", "quem me segue”.

Pesquisas realizadas em 2007 na Inglaterra e nos EUA, classificaram os usos do Twitter a partir de duas perspectivas: funcional (JAVA ET AL., 2007), a partir da análise do objetivo das mensagens tuitadas (Papos do cotidiano; Conversas; Compartilhamento de links; Difusão de notícias jornalísticas) e temático (MISCHAUD, 2007), a partir do levantamento dos assuntos tratados nos tweets e analisando a forma como os tuiteiros se apropriam e adaptam uma ferramenta de comunicação. No Brasil, Zago (2008, p.5) analisa os usos sociais do Twitter, "considerando-se o caráter de rede social da ferramenta, buscando identificar os usos sociais do Twitter, a partir dos tipos de capital social predominante percebido nas diferentes atualizações do sistema".

A taxonomia de Zago (2008) contextualiza cinco categorias de usos do Twitter na dimensão do capital social: 1. Compartilhamento de informação; 2. Trocas e conversações; 3. Metapostagens; 4. Pessoal; e 5. Ação coletiva. Considerando o perfil específico dos sujeitos observados, consideramos que além destas categorias há uma classificação nesta pesquisa que dá conta de uma apropriação comum a todos os sujeitos e que merece detalhamento e uma descrição própria: a da atividade docente.

Todos os dez sujeitos desta pesquisa são docentes. É comum em todos os perfis analisados, que a apropriação pedagógica predomine no Twitter. A atividade docente é a apropriação do sujeito que utiliza o Twitter com a finalidade de promover a relação ensino-aprendizagem. É esta a ação prioritária da docência. 
$\mathrm{Na}$ conversa abaixo, registrada entre o um dos sujeitos pesquisados e alguns seguidores alunos, por exemplo, além da dimensão cognitiva, relacionada à transmissão e aquisição de saberes, predominantemente presente na apropriação da atividade docente, todas as outras dimensões propostas por Bertolini e Bravo (2004) estão presentes: a relacional à medida que as relações que os sujeitos vivenciam são referenciadas; a normativa, a partir do momento que os sujeitos demonstram conhecer a norma de quantidade de caracteres do Twitter, por exemplo, fazendo ponderações curtas e objetivas; a institucional, visto que os sujeitos deixam claro pertencerem a um grupo social comum; e a confiança no ambiente social, que considera a confiança que os sujeitos alunos têm em questionar o professor a respeito de uma atividade avaliativa proposta por ele e do professor em ceder algumas dicas, tudo isso em ambiente online.

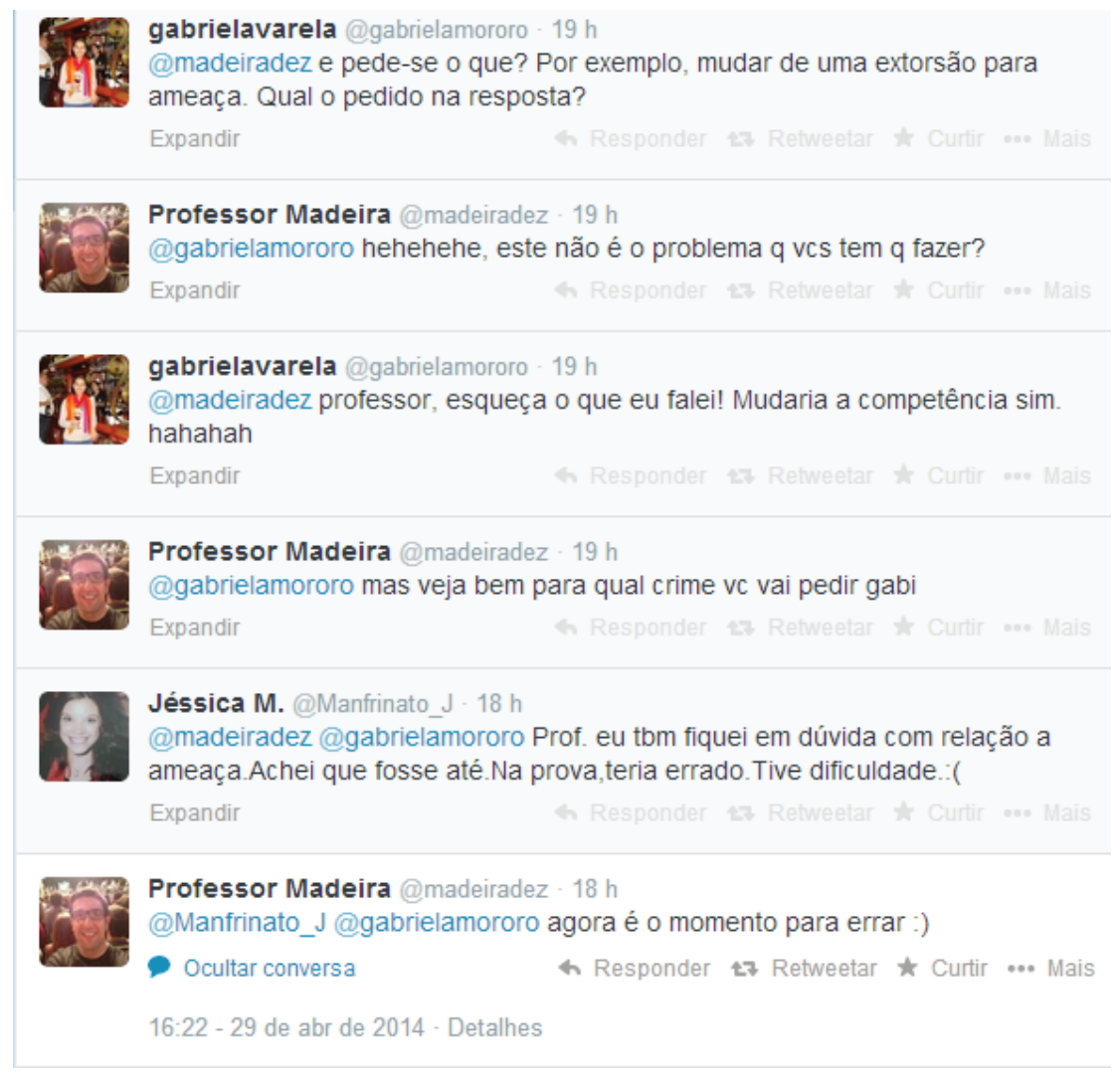

A apropriação do Twitter para a atividade docente, portanto, mobiliza dimensões de capital social, cria e institui ações docentes no SRS. Isso acontece pelo caráter social do Twitter que permite diversas apropriações para além da ideia inicial de disponibilizar e compartilhar informações. Os fundamentos da ação docente decorrem das referências de cada sujeito no seu processo de desenvolvimento social, além do seu contexto profissional. 
A partir da análise dos tweets da dimensão da docência, foram identificados quatro blocos que contém ações docentes específicas no Twitter: Produção de conteúdos; Dimensão didática; Compartilhamento e divulgação; Opinião e problematização.

Ao identificar e analisar as estratégias que os professores utilizam para construir visibilidade no Twitter foram destacadas sete estratégias mais recorrentes: publicizar privacidades, monitoramento do perfil, recomendação de outros usuários, participação de movimentos tipo \#FollowFriday, retuitar mensagens, utilizar hashtags e fazer menção a outros usuários. Todas estas estratégias resultam em maior visibilidade e popularidade no Twitter. Sujeitos mais populares e visíveis têm assim maior possibilidade de sucesso profissional.

Quadro 1 - Estratégias de visibilidade utilizadas pelos professores tuiteiros

\begin{tabular}{|c|c|}
\hline ESTRATEGIAS & UTILIZADAS POR \\
\hline Publicização da vida privada & $\begin{array}{c}\text { @madeiradez, @MissMoura, @Prof Adail, @idegasperi, } \\
\text { @Prof Jubilut }\end{array}$ \\
\hline Monitoramento & @MissMoura @Prof Adail, @Prof Jubilut, @idegasperi \\
\hline Recomendação de outros usuários & $\begin{array}{c}\text { @Prof Adail, @madeiradez, @profmarcoant, } \\
\text { @prof erival }\end{array}$ \\
\hline Participar do movimento \#FollowFriday & @idegasperi, @MissMoura \\
\hline Retweet & $\begin{array}{c}\text { @profmarcoant, @Prof Adail, @MissMoura, } \\
\text { @idegasperi, @prof erival, @madeiradez, } \\
\text { @professormazza, @ENEMmateusprado, @samadeu, } \\
\text { @Prof Jubilut }\end{array}$ \\
\hline Utilizar hashtags & $\begin{array}{c}\text { @profmarcoant, @Prof Adail, @MissMoura, } \\
\text { @idegasperi, @prof erival, @madeiradez, } \\
\text { @professormazza, @ENEMmateusprado, @samadeu, } \\
\text { @Prof Jubilut }\end{array}$ \\
\hline Menção & $\begin{array}{l}\text { @rof Adail, @idegasperi @Prof Jubilut, } \\
\text { @profmarcoant, @madeiradez, @professormazza, } \\
\text { @prof erival, @MissMoura }\end{array}$ \\
\hline
\end{tabular}

Fonte: os autores

A publicização $\neg$ da vida privada está associada ao apareSer (DAL BELLO, 2011) e ao uso confessional da internet (BAUMAN, 2011). No Twitter, os atores aprendem a administrar essa exposição e a promover-se. Compartilhar experiências triviais do cotidiano aproxima os atores que por vezes estão distantes. 


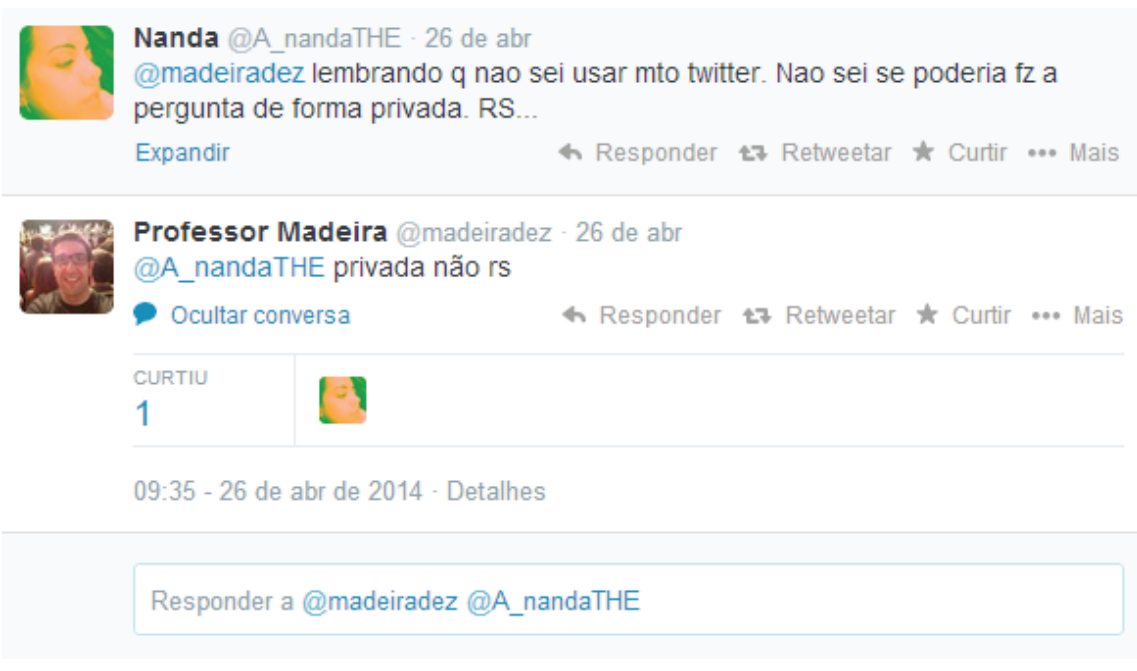

O que chamamos aqui de publicização da vida privada não está relacionado exclusivamente às exibições de privacidades muito íntimas, mas da publicização daquilo que é do cotidiano, do dia a dia das pessoas.

\section{Prof_Jubilut Fiz meu papel de cidadão e peguei um busão hj. Nã̃o tinha ar condicionado. Devia tá uns 200 graus dentro. Amanhã é carro neles!!! \#pobresofre \\ 5 Feb from Twitter Web Client}

A estratégia de tornar público aquilo que é da dimensão da vida privada cotidiana, em um espaço de interação onde o sujeito assume a postura profissional mais fortemente, está associada ao valor da visibilidade como um tipo de capital que aproxima os atores de uma rede, diminui as fronteiras, pessoaliza a relação. Um outro indicativo que ressalta a importância de ser visível na rede é o fato de que muitos usuários monitoram suas redes, na perspectiva de quem acessa, quantos replies e retuítes são feitos e quantas visualizações cada tweet recebe. 
Fi Professor Adail @Prof Adail · 11 de mai

novo status: pessoas que visitaram meu perfil twcm.me/LJUON

F.

Professor Adail @Prof Adail.8 de mai

Veja os usuários que acessaram seu perfil agora twcm.me/LJUON

Fit Professor Adail @Prof Adail·30 de abr

última atualização de visitantes do meu perfil twcm.me/LJUON

Fis

Professor Adail @Prof Adail.27 de abr

seu perfil foi visto por 3 pessoas nas últimas 2 horas twcm.me/LJUON

O monitoramento busca compreender a audiência de modo a perceber o que se tuíta e o que mais causa impacto positivo na rede social. Essa métrica pode auxiliar na construção de outras estratégias, fortalecimento das que estão dando certo, possibilitando alcançar um maior número de seguidores, o que torna o perfil mais visto.

É possível perceber que os atores utilizam ainda alguns elementos de reciprocidade e generosidade para conseguir aumentar sua popularidade de forma imbricada a visibilidade. Isso é feita por meio de três estratégias. A primeira é a recomendação de outros usuários. Ser generoso na rede, recomendando outros atores, associa um valor positivo ao perfil do ator social, atribuindo valor do nível da visibilidade ao ator recomendado.

Professor Madeira @madeiradez-11 h

Já pensaram q eramos a mesma pessoa rs. Mas se eu fosse vc eu seguiria o (1) NerdPai

Uma das arrobas mais bacanas por aqui

Expandir

A segunda estratégia é a de aumentar o número de seguidores participando do movimento \#FollowFriday ou \#FF. 

Obrigada pelo \#FF :) SEUS LINDOS.

21 Feb from Twitter Web Client

O movimento \#FollowFriday funciona também como uma recomendação de outros atores, o que configura uma ação de generosidade e é valorizado positivamente pelos atores sociais que, como@MissMoura e @idegasperi agradecem as recomendações. Essas estratégias evidenciam os atores atribuindo-lhes visibilidade.

E a terceira estratégia que auxilia na construção da visibilidade é a prática de retuitar ou dar RT, ou seja, replicar uma mensagem de alguém.

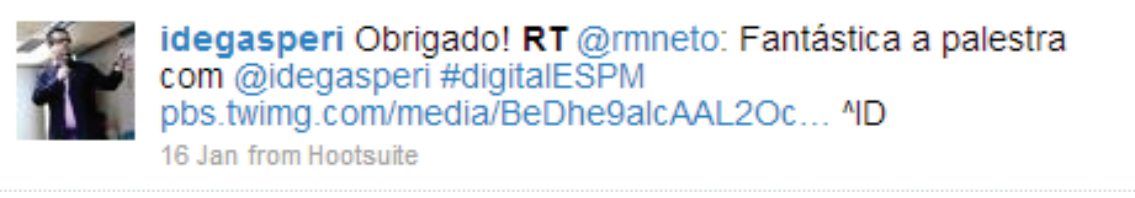

Muitas vezes, essa mensagem vem com algum comentário colocado manualmente pelo usuário como nos tweets acima ou como no exemplo abaixo, com um tweet que antecede o RT, ou seja, não é só replicar, mas chamar atenção para o RT. Além disso, os atores também retuítam comentários e menções feitos a partir de um tweet publicado.

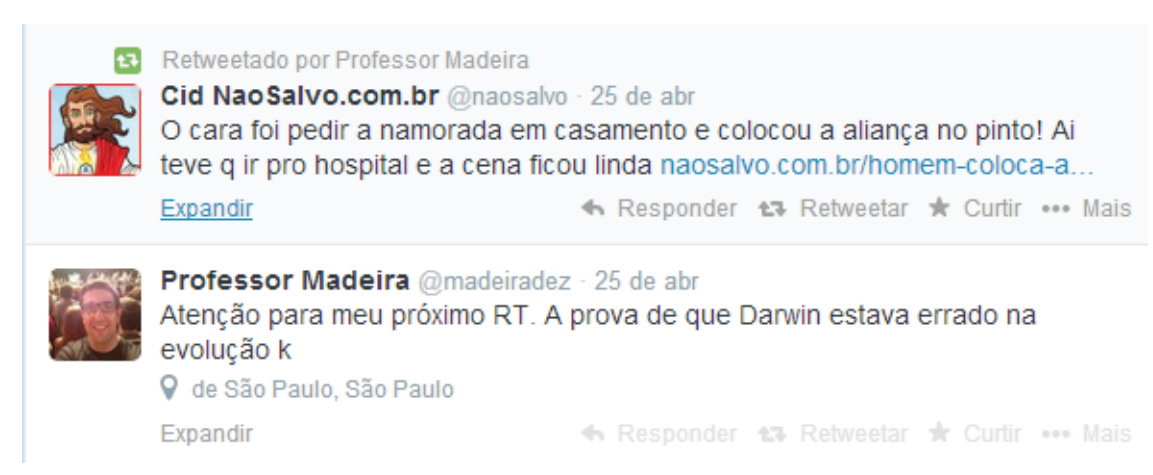

O que chamou a atenção durante a observação é que além de retuítarem postagens que consideravam interessantes para a sua rede, ou mesmo interações que efetivam com seus seguidores, todos os professores se utilizam de uma prática comum: a de retuitar os elogios que recebem dos alunos ou mesmo as menções de indicação que são feitas de cada um. 

acertos entre constitucional e humanos!!! Obrigadaaa Rumo a 2 fase.

14 Apr from Twitter for iPad retweeted by prof_erival

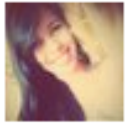

milenaalbernas @profmarcoant professor, não posso dizer que passei! MAS TENHO CERTEZA, gabaritei Ética! Vocêee é animaaal !

13 Apr from Twitter Web Client retweeted by profmarcoant

É possivel perceber nos tweets acima que eles possuem menção a um professor específico e uma avaliação positiva. Tweets como estes tem um valor considerável pois conferem credibilidade e reputação positiva. Essas postagens significam que os atores da rede estão avaliando o professor tuiteiro em sua timeline. Quando o professor replica essa informação para sua audiência ele amplia a sua visibilidade, mas não só isso, o faz com o aval de um seguidor ou de um aluno, construindo uma reputação positiva. Para Recuero e Zago (2010), a reputação está associada ao reconhecimento de um determinado ator por sua rede social.

Utilizar hashtags é uma estratégia de visibilidade muito pertinente e usual no Twitter e isso se repete no grupo de professores pesquisados. As hashtags constroem redes em torno de um tema e são responsáveis também por compor os TrendingTopics, relação dos assuntos mais comentados, populares visíveis. Quanto mais populares as hashtags utilizadas, maior visibilidade o ator social alcança.

Entre o grupo de professores há quatro situações bem pontuais: a utilização de hashtags populares; a utilização de hashtags institucionais, que vinculam o sujeito à sua instituição e confere visibilidade e reputação tanto ao ator quanto à instituição, como no tweet abaixo; e as hashtags criadas pelos professores para construir uma rede temática em torno de expressões que utilizam com sua audiência de alunos.

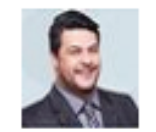

profmarcoant Essa última dica que eu postei é \#ANIMAL ... Se cair, já sabe, né ! Escreve ANIMAL na questão, tira foto e manda ! \#damasio

13 Apr from Twitter Web Client

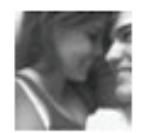

guiemari@profmarcoant Professor, errei só uma de Ética !! \#ANIMALLLLLL $14 \mathrm{Apr}$ from Twitter Web Client retweeted by profmarcoant 
Esse tipo de hashtags cria uma identidade, sentido de pertencimento a uma rede temática e uma aproximação entre os atores sociais. Todos estes elementos ajudam a construir visibilidade dos atores e da própria rede em torno da hashtag.

A menção é uma estratégia popular que evidencia o ator numa rede para a audiência. Quando um ator é mencionado, adquire visibilidade entre sua audiência e na audiência de quem fez a menção.

MissMoura @MissMoura. 5 de fev

O link original do post está aqui: As 25 negras mais influentes da internet \#25webnegras blogueirasnegras.org/2013/12/31/25-.

MissMoura@MissMoura · 5 de fev

Acabo de descobrir que o@BlogNegras me contemplou na lista das negras mais influentes da internet brasileira. QUANTA HONRA! :D

O exemplo de menção acima feito pela professora @MissMoura evoca um blog e uma premiação feita à professora. Ao mencionar o blog, a professora atribui visibilidade ao canal, mas também acumula capital social, pois compartilha uma premiação recebida por sua influência na internet.

Assim, a partir da análise dos tweets da dimensão da docência, foram identificados quatro blocos que contém ações docentes específicas no Twitter: Produção de conteúdos; Dimensão didática (compartilhamento síncrono de eventos; interação direta com a audiência; e aulas online); Compartilhamento e divulgação (compartilhamento de informação e notícia; divulgação de atividades acadêmicas, científicas ou profissionais); Opinião e problematização (opinião sobre temáticas cotidianas e polêmicas; desafios e problematizações). Considerando que todos os sujeitos desta pesquisa lançam mão dessas ações em uma public timeline, entendemos que eles desejam, de alguma forma dar visibilidade às suas ações.

\section{Considerações finais}

Se, de um lado, a publicização de ações docentes nos SRS fora do contexto curricular, especialmente no Twitter, ainda é uma experiência recente, de outro, milhares de pessoas estão cada vez mais acostumadas e fascinadas com o ato de narrar incessantemente a vida na internet.

Essas práticas expressivas de si e de suas ações profissionais e acadêmicas proliferam como expansão social. Isto significa, dentre outras coisas, que a forma por excelência pela qual cada sujeito se constrói na cibercultura é essa, vinculada ao com- 
partilhamento e a publicização de suas práticas. A máxima do nosso tempo é: não basta vivenciar, é preciso compartilhar cada desejo e experiência.

Nossa pesquisa concluiu que a visibilidade das ações docentes no Twitter remodelam as formas como os professores lidam com a socialização de saberes, com a dinâmica da aula, da interação com o aluno, mas também reconfiguram o papel do sujeito que é múltiplo num espaço público que é a internet. Essa reconfiguração em busca da visibilidade, da popularidade, de ter sua autoridade reconhecida e uma reputação positiva na rede está associada às dinâmicas e vivências em todos os contextos sociais.

O Twitter aproximou famosos e anônimos, professores e alunos, sujeitos comuns e celebridades, colocou quase que no mesmo patamar conhecidos e desconhecidos. Desse modo, os mitos se tornaram próximos, muito mais reais e, especialmente, mais humanos. De outro lado, de modo espontâneo ou perseguindo popularidades, a toda hora, anônimos se tornam populares, vivem seus momentos de fama. Os professores, corpus desta investigação, alcançam patamar de tornam-se celebridades borbulhantes.

Outra conclusão da pesquisa é que no Twitter toda e qualquer pessoa pode ser importante influenciadora da cultura globalizada. As estratégias que o grupo de professores pesquisado utilizam estão associadas à compreensão de apareSer, um acúmulo de reflexões sobre a construção e promoção de subjetividades em espaços de alta visibilidade no contexto da cibercultura. Deste modo, a visibilidade é investimento, custo e valor acumulado que associa tantos outros valores para os sujeitos em seus agregados sociais.

Entendemos que a valorização social enquanto patamar a ser atingido por meio das estratégias de visibilidade, não se encerra em si, pois a visibilidade que possibilita essa valorização, pode implicar em valorizações de outras naturezas, tão importantes quanto. Este estudo concluiu que a visibilidade aumenta o reconhecimento social. Um professor mais visível, que possui muitos seguidores, é mais citado, recomendado e essa visibilidade faz com que ele seja, por exemplo, mais presente em eventos acadêmicos, convidado para falar sobre as temáticas em veículos midiáticos.

Nosso estudo nos permite sustentar o argumento de que a visibilidade no Twitter é um capital social forjado por meio das estratégias que os sujeitos instituem no SRS. Ser visível na rede indica uma valorização social preponderante na cibercultura. No caso de docentes, este valor tem uma importância singular, considerando que as ações que eles realizam no Twitter são potencialmente visíveis e, portanto, configuram-se ações educativas que ecoam em suas esferas sociais.

\section{Referências}

AMARAL, A. Autonetnografia e inserção online. O papel do pesquisador-insider nas subculturas da web. In: Revista Fronteiras - Estudos Midiáticos, São Leopoldo, jan-abr 2009. Disponível em: <http://www.fronteiras.unisinos.br/pdf/62.pdf>. Acesso em: 20 mar. 2014.

BAUMAN, Zygmunt. 44 cartas ao mundo líquido moderno. Tradução Vera Pereira. Rio de Janeiro: Zahar, 2011. 
BERTOLINI, S.; BRAVO, G. Social capital, a multidimensional concept. 2004. Disponível em: <http://web.archive.org/web/20030318075349/http://www.ex.ac.uk/shipss/politics/research/socialcapital/other/bertolini.pdf>. Acesso em: 10 abr. 2014.

BOYD, Danah M.; ELLISON, Nicole B. Social Network Sites: Definition, History, and Scholarship. Journal of Computer- Mediated Communication. v. 13, n. 1, 2007. p. 210-230. Disponível em: <http://www.blackwell-synergy.com/doi/pdf/10.1111/j.1083-6101.2007.00393.x> Acesso em: 11 ago. 2012.

DAL BELLO, Cíntia. Visibilidade Mediática Cibercultural: apontamentos sobre a fenomenologia do "apareSer". In: Simpósio Nacional de Cibercultura, 5., 2011. São Paulo: Associação Brasileira de Pesquisadores em Cibercultura, 2011. Disponível em: <http://pt.slideshare.net/ CntiaDalBello/visibilidade-meditica-cibercultural-apontamentos-sobre-a-fenomenologia-do -apareser>. Acesso em: 29 nov. 2013.

JAVA, A.; SONG, X.; FINN, T.; TSENG, B. Why We Twitter: Understanding Microblogging Usage and Communities. Procedings of the joint 9th WEBKDD, 2007. Disponível em: <http:// ebiquity.umbc.edu/get/a/publication/369.pdf>. Acesso em: 30 abr. 2014.

KOZINETS, R. V. The Field Behind the Screen: Using Netnography for Marketing Research in Online Communities. 2002. Disponível em: <http://www.marketingpower.com/content18255.php> Acesso em: 29 nov. 2009.

LASTA, Elisângela; BARRICHELLO, Eurgênia M. Rocha. Proposta de uma matriz de análise de estratégias sociotécnicas de visibilidade e legitimidade presentes em blogs corporativos. In: Intercom - RBCC. São Paulo, v.36, n.1, p. 249-268, jan./jun. 2013. Disponível em: < http:// www.scielo.br/pdf/interc/v36n1/13.pdf>. Acesso em: 20 abr. 2014.

MISCHAUD, E. Twitter: Expressions of the Whole Self. Londres: LSE, 2007. Dissertação (Mestrado), London School of Economics, Department of Media and Communications, 2007. Disponível em: <http://wiredpen.files.wordpress.com/2009/05/mischaud_final.pdf>. Acesso em: 29 abr. 2014.

ORIHUELA, J. L. Mundo Twitter: Una guía para comprender y dominar la plataforma que cambió la red. Barcelona: Alienta Editorial, 2011.

RECUERO, Raquel; ZAGO, Gabriela. RT, por favor: considerações sobre a difusão de informações no Twitter. Revista Fronteira, v. 12, p. 69-81, Unisinos, 2010. Disponível em: < http:// www.fronteiras.unisinos.br/pdf/88.pdf >. Acesso em: 20 maio 2012.

SANTAELLA, Lúcia; LEMOS, Renata. Redes sociais digitais: a cognição conectiva do Twitter. São Paulo: Paulus, 2010.

SANTANA, Camila Lima S; COUTO, Edvaldo Souza. A publicização da vida privada no Twitter. In: Revista Fronteiras - Estudos Midiáticos. São Leopoldo, v. 14 n.1, p. 31-39, janeiro/abril 2012. Disponível em: $<$ http://revistas.unisinos.br/index.php/fronteiras/article/view/ fem.2012.141.04/741>. Acesso em: 24 nov. 2013.

ZAGO, Gabriela. S. Usos sociais do Twitter: proposta de tipologia a partir do capital social. 2008. Disponível em: <http://www.pontomidia.com.br/raquel/teorica.htm>. Acesso em: jul. 2013.

\section{Notas}

\footnotetext{
${ }^{1}$ Fonte: <http://tweetreach.com>. O TweetReach é uma ferramenta que mede o impacto dos tweets, analisa o alcance das interações dos tuiteiros e cria métricas sociais de monitoramento. A versão gratuita disponibiliza um relatório com dados básicos, mas essenciais para esta pesquisa, como alcance dos tweets, nível de exposição e principais colaboradores dos perfis. Esses níveis levam em consideração os seguidores dos perfis, os seguidores dos seguidores e assim sucessivamente. Com fins de métrica para seleção dos sujeitos, estabelecemos que o nível mínimo de alcance estimado das mensagens e de exposição seriam 50 mil contas.
} 
* Professora doutora do Instituto Federal de Educação, Ciência e Tecnologia Baiano, Salvador, Bahia, Brasil.

** Professor doutor da Universidade Federal da Bahia, Salvador, Bahia, Brasil.

\section{Correspondência}

Camila Lima Santana e Santana - Instituto Federal de Educação, Ciência e Tecnologia Baiano, Pró-Reitoria de Desenvolvimento Institucional. Rua dos Rouxinol, 115 - Imbuí. CEP: 41720052. Salvador, Bahia, Brasil.

E-mail: camilalimasantana@gmail.com - edvaldosouzacouto@gmail.com

Recebido em 07 de junho de 2016

Aprovado em 20 de abril de 2017 
